\title{
Comparison of Spiritual Experiences and Hope between Breast Cancer Survivors and Healthy Counterparts
}

\author{
Mahsa Rashidi ${ }^{1}$, Anahita Khodabakhshi-koolaee ${ }^{2}$, Hasanali Vahedian Ardakani ${ }^{3}$
}

1. Department of Counseling and Psychology, Tehran North Branch, Islamic Azad University, Tehran, Iran

2. Department of Psychology and Education, Faculty of humanities, Khatam University, Tehran, Iran

3. Department of Oncology, Shahid Sadoughi University of Medical Sciences and Health Services, Yazd, Iran

\begin{abstract}
Background and objectives: Breast cancer is the most common type of cancer and the second leading cause of cancer death in women aged 35-54 years. Belief in God and spiritual experiences can help the patients endure physical pain and enhance their physical and mental well-being. The purpose of this study was to compare spiritual experiences and hope between survivors of breast cancer and healthy counterparts.

Methods: This descriptive case-control study was performed in 2018, on 85 breast cancer survivors and 85 healthy women from the city of Yazd (Iran) who were selected via availability sampling. The subjects completed the hope scale (developed by Snyder) and the Daily Spiritual Experience Scale (developed by Underwood and Teresi). Data were analyzed using independent t-test at significance level of 0.05 .

Results: The mean score of spiritual experiences was significantly higher in breast cancer survivors $(81.2 \pm 10.47)$ than in healthy counterparts $(71.03 \pm 13.18)(\mathrm{P}<0.001)$. However, there was no significant difference in the mean score of hope between breast cancer survivors $(30.47 \pm 5.29)$ and women without breast cancer (31.3 \pm 5.67$)(\mathrm{P}=0.28)$.

Conclusion: Given our results, it is suggested to design and offer workshops and trainings on hope and hope-based therapies for highlighting the role of hope in improving disease status and patients' mental well-being.
\end{abstract}

Keywords: Hope, Spiritual experiences, Breast cancer, Women

$\begin{array}{lll}\text { Received: 2019/03/19 } & \text { Revised:2019/04/22 } & \text { Published:2019/08/04 }\end{array}$

*Correspondence: Anahita Khodabakhshi-koolaee, Department of Psychology and Education, Faculty of humanities, Khatam University, Tehran, Iran

Tel: +98-2189174119

Email: a.khodabakhshid@khatam.ac.ir 


\section{INTRODUCTION}

Breast cancer is the most common type of cancer and the second leading cause of cancer death in women aged 35-54 years (1). Each year, more than one million new cases are diagnosed and 600,000 people die from breast cancer worldwide (2). In Iran, about 7,778 women are diagnosed with breast cancer every year. The disease affects women of all ages, but women aged 45 to 55 years are at a higher risk. The 5-year survival rate of these patients varies between $48 \%$ and $84 \%$ (3). Breast cancer is associated with sexual dysfunction, self-negative image, communication problems, hair loss, weight gain, fatigue, restriction of shoulder movement, pain, wound infection, surgical site sensory disturbance and dry skin $(4,5)$. Breast cancer surgeries can result in breast deformity or removal of one or both breasts. Surgical methods affect various aspects of a woman's psychosocial functioning such as identity, confidence, mood, sexual desire, self-satisfaction and quality of life. In addition, body image issues are associated with stress, depression, social withdrawal and anxiety of being rejected by the partner. Fear of rejection and being unattractive from the point of view of spouse/partner and other important people in the patient's life are a major concern for women with body image problems (6-8).

Since cancer patients usually experience negative thoughts after being diagnosed, the remembrance of God as part of a spiritual healing process could help them feel more relaxed. This process is based on strengthening the relationship with God, which is the source of absolute power $(9,10)$. According to Gesselman and colleagues, religious/spiritual experiences are religious attitude, practical aspects, mental health, supernatural beliefs and religious practices, while considering religion as a human being's connection to a greater being (11). A study by Bekelman et al. showed that application of spiritual concepts in the treatment of cancer patients could improve the psychological, spiritual and overall well-being of the patients while reducing the level of depression (12). Cancer patients with a desirable level of spiritual well-being enjoy life and feel more at peace even when dealing with cancer-related problems, such as fatigue or pain $(13,14)$.

A large number of cancer patients feel hopeless. Hope is a characteristic that involves goal setting, power of planning, the will to achieve goals, attention to barriers and the ability to remove them, and enhancing individual performance (15). Hopeful people are generally more positive and have effective social relationships. These people can effectively deal with psychosocial stress by utilizing coping strategies, such as reassessment and problem solving. Therefore, psychiatrists and psychologists have considered hope as a general positive expectation for achieving a goal $(15,16)$.

Studies have shown that the average age of developing breast cancer in Iran is lower than in western countries. Thus, screening, diagnosis and control of this disease and associated psychological problems are crucial (3). On the other hand, cancer patients use religion and spirituality to reduce psychological and physiological stress during the disease process $(13,14)$. In this study, we aimed to compare spiritual experiences and hope between survivors of breast cancer and women without cancer.

\section{MATERIALS AND METHODS}

The purpose of this descriptive case-control study was to evaluate religious experiences and hope in 85 breast cancer survivors and 85 women without cancer who were referred to hospitals and medical centers of Yazd (Iran) in 2018. Subjects were selected via availability sampling. The list of breast cancer survivors were retrieved from the Shahid Sadooghi, Shohadaye Kargar and Mortaz hospitals in Yazd. Written informed consent was obtained after explaining the research objectives. The subjects were 30-60 years old, married, with at least a high school diploma and without concurrent physical or mental disorder at the time of diagnosis. Exclusion 
criteria were exacerbation of disease and failure to complete the questionnaires.

The Snyder's adult hope scale (1991) was used to measure hope. This self-administered questionnaire has 12 questions that are scored based on an eight-point Likert-type scale ranging from completely disagree (1 point) to completely agree (8 points). The questionnaire consists of a thinking subscale (4 questions), a paths subscale (4 questions) and miscellaneous questions (17). In a previous study, the validity coefficient was estimated as 0.76 for the thinking subscale and 0.75 for the paths subscale (18). In another study, the reliability of the questionnaire was confirmed with Cronbach's alpha coefficient of 0.86 for the hope scale, 0.77 for the thinking subscale and 0.79 for the paths subscale (19). In the present study, the Cronbach's alpha for this questionnaire was
0.82. Spiritual experiences were measured using the Daily Spiritual Experience Scale (developed by Underwood), which has 16 items on three dimensions of God presence, connection with God and responsibility towards others. The items are scored using a modified six-point Likert scale, and higher scores reflect more spiritual experiences (20). Taghavi and Amiri reported a Cronbach's alpha coefficient of 0.96 for this questionnaire (21). In the present study, the Cronbach's alpha coefficient of this questionnaire was 0.89 .

Finally, data were analyzed in SPSS software (version 21) using the Levene's test and independent t-test.

\section{RESULTS}

Table 1 presents the frequency of subjects based on age and marital status.

Table 1. Frequency of subjects based on age and marital status

\begin{tabular}{|c|c|c|c|}
\hline \multicolumn{2}{|c|}{ Variable } & Survivors of breast cancer & Women without breast cancer \\
\hline \multirow{3}{*}{ Age group } & Under 35 & $14(16.5 \%)$ & $31(36.5 \%)$ \\
\cline { 2 - 4 } & $35-42$ & $16(18.8 \%)$ & $26(30.6 \%)$ \\
\cline { 2 - 4 } & $43-52$ & $22(25.9 \%)$ & $19(22.4 \%)$ \\
\cline { 2 - 4 } & 53 or over & $33(38.8 \%)$ & $9(10.6 \%)$ \\
\hline \multirow{2}{*}{ Marital status } & Single & $6(7.1 \%)$ & $8(9.4 \%)$ \\
\cline { 2 - 4 } & Married & $79(92.9 \%)$ & $77(90.6 \%)$ \\
\hline
\end{tabular}

As shown in table 2, mean score of spiritual experiences was significantly higher in survivors of breast cancer than in women without breast cancer $(\mathrm{P}<0.001)$. However, the mean score of hope did not differ significantly between the two groups $(\mathrm{P}<0$. 28).

Table 2. Comparison of mean score of spiritual experiences and hope between the two groups using independent t-test

\begin{tabular}{|c|c|c|c|c|c|c|c|c|c|}
\hline \multirow{2}{*}{ Variable } & \multirow{2}{*}{ Groups } & \multirow{2}{*}{$\begin{array}{l}\text { Mean } \\
\text { Score }\end{array}$} & \multirow{2}{*}{$\begin{array}{l}\text { Standard } \\
\text { deviation }\end{array}$} & \multirow{2}{*}{$\begin{array}{c}\text { Equality } \\
\text { of } \\
\text { variance }\end{array}$} & \multicolumn{2}{|c|}{ Levene's test } & \multirow{2}{*}{$\mathbf{T}$} & \multirow{2}{*}{$\begin{array}{l}\text { Degree of } \\
\text { freedom }\end{array}$} & \multirow{2}{*}{ P-value } \\
\hline & & & & & $\mathbf{P}$ & $\mathbf{F}$ & & & \\
\hline $\begin{array}{c}\text { Spiritual } \\
\text { experiences }\end{array}$ & $\begin{array}{c}\text { Breast } \\
\text { cancer } \\
\text { survivors }\end{array}$ & 10.46 & 81.20 & $\begin{array}{c}\text { Equality } \\
\text { of } \\
\text { variance }\end{array}$ & 0.014 & 6.065 & 71.528 & 84 & 0.0001 \\
\hline
\end{tabular}


Journal of Clinical and Basic Research (JCBR). 2019; 3(2): P 21-26.

\begin{tabular}{|c|c|c|c|c|c|c|c|c|c|}
\hline & $\begin{array}{c}\text { Women } \\
\text { without } \\
\text { breast } \\
\text { cancer }\end{array}$ & 13.19 & 71.03 & & & & 49.66 & & \\
\hline \multirow[b]{2}{*}{ Hope } & $\begin{array}{c}\text { Breast } \\
\text { cancer } \\
\text { survivors }\end{array}$ & 30.27 & 5.29 & \multirow{2}{*}{$\begin{array}{l}\text { Equality } \\
\text { of } \\
\text { variance }\end{array}$} & \multirow[b]{2}{*}{0.004} & \multirow[b]{2}{*}{28.08} & 53.05 & \multirow[b]{2}{*}{84} & \multirow[b]{2}{*}{0.28} \\
\hline & $\begin{array}{c}\text { Women } \\
\text { without } \\
\text { breast } \\
\text { cancer }\end{array}$ & 31.20 & 5.67 & & & & 50.89 & & \\
\hline
\end{tabular}

\section{DISCUSSION}

Our results showed that spiritual experiences and hope differ between survivors of breast cancer and women without breast cancer. This finding was in line with findings of Salsman et al. (13) and Visser et al. (14) that also demonstrated that cancer patients benefit from spiritual experiences and hope for coping with life's problems and difficulties.

Bekelman et al. reported that using spiritual concepts in the treatment of cancer patients could improve patients' psychological wellbeing, spirituality and lifestyle while reducing the rate of depression. Having a strong sense of spirituality helps patients cope with the illness (12). It is thought that breast cancer survivors are better at spiritual experiences compared to healthy counterparts. In addition, they often experience the presence of God and some degree of continuity in all aspects of life (11).

In the present study, the mean score of hope did not differ significantly between breast cancer survivors and women without breast cancer. Encountering cancer itself can be an extremely stressful event that could negatively affect different aspects of an individual's mental and physical health (2223). The mental stress caused by the disease is so high that often leaves no hope for the patients (8). Fearing illness and death is not the only concern of cancer patients, but sometimes side effects of therapy, such as hair loss, cumulative fatigue, lethargy and especially changes in breast appearance and sexual dysfunction lead to depression and various mental health problems $(8,9)$. In general, spiritual experiences and hope can help patients cope with the physical and psychological pressures of chronic diseases (9).

The limitations of this study include implementing the available sampling method and not assessing other factors affecting hope and life expectancy.

\section{CONCLUSION}

Our results indicate that breast cancer survivors benefit from more spiritual experiences compared to healthy counterparts. However, there is no significant difference between the two groups in terms of hope. Since loss of hope in life could weaken problem-solving skills and lead to devastating outcomes, health centers and the patients' relatives should help improve their hope and pave the way for treatment.

\section{ACKNOWLEDGEMENTS}

We would like thank the participants and all those who contributed to this research.

\section{DECLARATIONS}

\section{Funding}

Not applicable.

\section{Ethics approvals and consent to participate}

The study has been approved by the ethics committee of the Islamic Azad University, North Tehran Branch, Tehran, Iran (code: 157216029611019). 


\section{Conflict of interest}

The authors declare that there is no conflict of interest regarding the publication of this article.

\section{REFERENCES}

1. Humpel, N., \& Jones, SC. I don't really know, so it's a guess: women's reasons for breast cancer risk estimation. Asian Pacific Journal of Cancer Prevention, 2004; 5 (4): 428-32.

2. Holt CL, Kyles A, Wiehagen T, Casey C. Development of a spiritually based breast cancer educational booklet for African-American women.Cancer Control,2003; 10 (5 suppl): 37-44. [DOI:10.1177/107327480301005s06]

3. Akbari ME, Mirzaei HR, Soori H. 5 year survival of breast cancer in Shohada-e-Tajrish and Jorjani hospitals. Hakim Research Journal. 2006 Jul 15;9(2):39-44.

4. Kissane D, White K, Cooper K, Vitetta L. Psychosocial impact in the areas of body image and sexuality for women with breast cancer. The national breast cancer center.2004.

5. Koolaee AK, Falsafinejad MR, Akbari ME. The effect of stress management model in quality of life in breast cancer women. Iranian journal of cancer prevention. Iran J Cancer Prev. 2015; 8(4): e3435. [DOI:10.17795/ijcp-3435]

6. Pilarski DJ. The Experience of younger women diagnosed with breast cancer involved in dance/movement therapy with regards to body image and sexuality(dissertation). College of Nursing and Health Professions Drexel Univ USA.2008.

7. Helms, RL., Ohea, EL., \& Corso, M. Body image issues in women with breast cancer. Psychology, Health \& Medicine, 2008;13(3): 31325. [DOI:10.1080/13548500701405509]

8. Tel, H., Tel, H., \& Dogan, S. Fatigue, anxiety and depression in cancer patients. Neurology, Psychiatry and Brain Research,2011; 17(2), 42-5. [DOI:10.1016/j.npbr.2011.02.006]

9. Amerifar M, Khodabakhshi Koulayi A, Sanagoo A. Comparison of Spiritual Experiences and Distress Tolerance between Women with Type 2 Diabetes and Healthy Counterparts: A
Cross-Sectional Study . Journal of clinical and basic research. 2019; 3 (1) :23-28 . URL: http://jcbr.goums.ac.ir/article-1-192-en.html

10. Khodabakhshi-Koolaee A, Heidari F, Motlagh FZ. The effect of mixed prayer and positive psychology group therapy on life meaning and death anxiety among elderly women with physical-motor disabilities. Journal of Research on Religion \& Health. 2018;4(2):16-28.

11. Gesselman AN, Bigatti SM, Garcia JR, Coe K, Cella D, Champion VL. Spirituality, emotional distress, and post-traumatic growth in breast cancer survivors and their partners: an actorpartner interdependence modeling approach. Psycho-Oncology. 2017;26(10):1691-9.

[DOI:10.1002/pon.4192]

12. Bekelman D B. , Dy S M., Becker D M. , Wittstein IS. , Hendricks D E., Yamashita T E. \& Gottlieb S H. Spiritual well-being and depression in patients with heart failure. Journal of General Internal Medicine,2007; 22 (4): 470-477. [DOI:10.1007/s11606-006-0044-9]

13. Salsman JM, Pustejovsky JE, Jim HS, Munoz AR, Merluzzi TV, George L, Park CL, Danhauer SC, Sherman AC, Snyder MA, Fitchett G. A meta-analytic approach to examining the correlation between religion/spirituality and mental health in cancer. Cancer. 2015 ;121(21):3769-78. [DOI:10.1002/cncr.29350]

14. Visser A, Garssen B, Vingerhoets A. Spirituality and well-being in cancer patients: a review. Psycho-oncology. 2010;19(6):565-72. [DOI:10.1002/pon.1626]

15. Snyder CR, editor. Handbook of hope: Theory, measures, and applications. Academic press; 2000 Jun 7.

16. Simão $T$, Caldeira $S$, de Carvalho $E$. The effect of prayer on patients' health: systematic literature review. Religions. 2016;7(1):11. [DOI:10.3390/rel7010011]

17. Grewal, P. K., \& Porter, J. Hope theory: a framework for understanding Death studies. Washington,2007; $\quad 31(2)$ : 131-154. [DOI:10.1080/07481180601100491] 
18. Alexander, E. S., \& Onwuegbuzie, J. A. Academic procrastination and the role of hope as a coping strategy. Personality and individual differences, 2007; $\quad$ 42(7): $\quad$ 1301-1310. [DOI:10.1016/j.paid.2006.10.008]

19. Kermani Z., Khodapanahi M, Heydari M. S. Snyder Hope Scale Psychometric Features. Applied Psychology. 2011;5(3):7-23. [In Persian].

20. Underwood LG, Teresi JA. The daily spiritual experience scale: Development, theoretical description, reliability, exploratory factor analysis, and preliminary construct validity using healthrelated data. Annals of Behavioral Medicine. 2002;24(1):22-33.

[DOI:10.1207/S15324796ABM2401_04]

21. Taghavi S. HR., Amiri H. Psychoanalysis Characteristic Investigation Daily Spiritual Experience Scale (DSES). Bi-quarterly Journal of Islamic Education, 2010;5(10): 151-167. [In Persian]

22. Jim HS, Pustejovsky JE, Park CL, Danhauer SC, Sherman AC, Fitchett G, Merluzzi TV, Munoz AR, George L, Snyder MA, Salsman JM. Religion, spirituality, and physical health in cancer patients: A meta-analysis. Cancer. 2015;121(21):3760-8. [DOI:10.1002/cncr.29353]

23. khodabakhshi-koolaee A, Farhangi D. Relationship of Spiritual Experiences and Hope with Living in Present among Men with Cancer in Tehran. Journal of Research Religion \& Health. 2019; 5(2): 75- $88 . \quad$ doi: [DOI:10.22037/jrrh.v5i2.19158.] 